Asian J. Med. Biol. Res. 2018, 4 (4), 406-415; doi: 10.3329/ajmbr.v4i4.40114

\author{
Asian Journal of \\ Medical and Biological Research \\ ISSN 2411-4472 (Print) 2412-5571 (Online) \\ www.ebupress.com/journal/ajmbr
}

\title{
Article \\ Comparative histomorphological study of non affected and affected bile duct and gall bladder by fascioliasis in Black Bengal Goat
}

Md. Reazul Islam ${ }^{1 *}$, Rashida Khaton ${ }^{2}$, Md. Aktharul Alam³ ${ }^{3}$ Md. Jalal Uddin Sarder ${ }^{2}$ and Md. Najmul Hassan Parvez $^{3}$

${ }^{1}$ Department of Preclinical Courses, Faculty of Veterinary and Animal Sciences, Gono Bishwabidyalay, Savar, Dhaka-1344, Bangladesh

${ }^{2}$ Department of Veterinary and Animal Sciences, University of Rajshahi, Rajshahi-6205, Bangladesh

${ }^{3}$ Department of Anatomy and Histology, Hajee Mohammad Danesh Science and Technology University, Dinajpur-5200, Bangladesh

*Corresponding author: Md. Reazul Islam, Department of Preclinical Courses, Faculty of Veterinary and Animal Sciences, Gono Bishwabidyalay, Savar, Dhaka-1344. E-mail: reazuldvm@gmail.com

Received: 07 December 2018/Accepted: 26 December 2018/ Published: 30 December 2018

\begin{abstract}
The purpose of this study was to comparative histomorphological investigation of the non affected and affected bile duct and gall bladder by fascioliasis in Black Bengal goat. The average weight of affected gall bladder was $26.10 \pm 0.70 \mathrm{gm}$ which was significantly $(\mathrm{p}<0.001)$ higher than non affected gall bladder $(19.40 \pm 0.96 \mathrm{gm})$. The average length and girth of affected gall bladder were $10.30 \pm 0.37 \mathrm{~cm}$ and $8.24 \pm 0.30 \mathrm{~cm}$, respectively which were also significantly $(\mathrm{p}<0.001)$ higher than the length $(6.10 \pm 0.30 \mathrm{~cm})$ and Girth $(5.85 \pm 0.25 \mathrm{~cm})$ of non affected gall bladder of Black Bengal Goat. The gross changes in acute form, thickening of the bile ducts and fibrosis in a portal area due to chronic fascioliasis was found in case of affected bile duct but were not found in case of non affected liver. A brownish exudates and a number of mature Fasciola gigantica were found in the lumen. The adult Fasciola gigantica was noticed in cross section in the lumen of the thickened bile ducts. Acute pathological lesions could only be produced by developing flukes prior to their entry to the bile ducts. Microscopically the epithelial layer of the bile ducts were seen to the partially disintegrated, but simultaneous proliferation of epithelial cells occurred. Thickening of the bile ducts was the result of connective tissue proliferation. Deposition of bile pigment in the tissue space and bile duct in some parts showed periductal cellular infiltrations, mainly neutrophiles, lymphocyte and eosinophiles. No calcification in the wall of the bile ducts in chronic Fascioliasis in goat could be seen in this study. The gall bladder was very dark usually contained blood clots, the consistency of bile was also very dense. Microcopically hyperplasia of the tubuloalveolar glands and numerous eggs were seen in the bile of infected goat which were absence in case of non infected goat.
\end{abstract}

Keywords: histomorphological; bile duct; gall bladder; fascioliasis; Black Bengal goat

\section{Introduction}

Goats as far as known were probably the first domestic ruminant after dogs around 9000-7000 BC (Herre and Rohrs, 1973). There is very little information about the origin of dwarf goats mostly found in this region. It is believed that Asiatic breeds of domestic goats are generally considered to derive from a single wild species Capra hircus aegagrus. The dwarf goat might be descended from a different origin and perhaps from African ancestors (Epsterin, 1971). Black Bengal goats are dwarf breed and are known to be famous for its adaptability, higher disease resistance, fertility, fecundity, early sexual maturity, larger litter size, delicacy of meat and superior skin quality (Devendra and Burns, 1983; Husain et al., 1998). However, some authors reported that their growth rate is slow, milk yield is as low that sometimes it is not sufficient for their kids and higher kid 
mortality (Amin et al., 2000, 2001; Chowdhury et al., 2002). Though majorities of the Black Bengal bear black coat color, black and white, brown, brown and white and white coat colors are also common in the Black Bengal population. Black Bengal goat constitutes nearly $90 \%$ of the total goat population of the country and the remaining are Jamunapari and their crosses (Husain et al., 1998). Parasitism is one of the main causes limiting livestock productions in most of the tropical and sub-tropical countries of the world. In Bangladesh, parasitism has been considered as one of the major constraints of livestock production (Jabbar and Hag, 1983). The incidence of parasitic diseases in the domestic ruminants of Bangladesh is also high and as a result hardly any livestock industry could develop here. Besides a large number of helminth parasites these are constantly deteriorating the health and productivity of the ruminants, Fasciola gigantica is by far the pre-dominant species of outstanding importance. The pathogenic effect of this parasite is extended over a large number of domestic ruminants; cattle, sheep, goats and buffaloes are mostly affected and drain a substantial economic loss to the country annually. Infection with Fasciola gigantica is regarded as one of the most common single helminth infection of ruminants in Asia and Africa (Hammond and Sewell, 1990). This disease causes enormous economic losses all over the world and these losses are due to reduction in milk and meat production, condemnation of liver, loss of draught power, reproductive failure and mortality (Diaw et al., 1998). The World Health Organization (WHO, 2006) has estimated that 2.4 million people are infected with Fasciola hepatica and a further 180 million are at risk of infection. So, for controlling the disease in this area, appropriate preventive control strategies have to be designed to reduce the impact of the disease on goat production in Bangladesh. Reazul et al., 2015 reported that the average weight of affected livers was $511.20 \pm 14.10$ gm which was significantly $(\mathrm{p}<0.001)$ higher than non affected livers $(371.70 \pm 13.25 \mathrm{gm})$. The average length and girth of affected liver were $27.50 \pm 0.63 \mathrm{~cm}$ and $34.00 \pm 0.71 \mathrm{~cm}$, respectively which were also significantly $(\mathrm{p}<0.001)$ higher than the length $(21.80 \pm 0.61 \mathrm{~cm})$ and girth $(26.60 \pm 0.80 \mathrm{~cm})$ of non affected liver of Black Bengal goat. The gross changes in acute form, affected livers were enlarged than normal. The livers were slightly swollen with rounded edges and the color became paler than normal. The capsule was more or less thick, opaque and rough than normal smooth thin capsule. The gross changes of the liver in chronic fascioliasis characterized by increase in the size of the organ due to inflammatory changes in the parenchyma and fibrosis of the bile ducts containing adult flukes. In acute cases microscopic changes were found mainly in the portal area. The grossly visible spots or tracks were represented by the presence of numerous eosinophils admixed with few lymphocytes and monocytes in the parenchyma of liver and accompanied by hemorrhage and edema. In chronic fascioliasis the hemorrhagic tracks or tunnels were represented by the areas infiltrated with fibroblasts admixed with neutrophils, lymphocytes and few mononuclear cells in the area previously migrated by young flukes. Among many parasitic problems of farm animals, Fascioliasis is a major disease, which imposes direct and indirect economic impact on livestock production, particularly of sheep and cattle (Hammond 1990; Menkir et al., 2007), Swai and Unlicky (2009) state that the total economic loss incurred as a result of condemnation of infected livers due to all causes and Fascioliasis was approximately 2,096 US\$ and 1,780 US\$ respectively. Losses due to weight loss were estimated to be 5,943 US\$. There are limited information on histomorphological study of non affected and affected bile duct and gall bladder by fascioliasis in Black Bengal goat. So the present study has been undertaken to evaluate the comparative histomorphological study of non affected and affected bile duct and gall bladder by fascioliasis in Black Bengal goat.

\section{Materials and Methods}

\subsection{Experimental area and duration}

The investigation was carried out in the Department of Anatomy and Histology, Faculty of Veterinary and Animal Science, Hajee Mohammad Danesh Science and Technology University, Dinajpur. Livers of goats were collected from different slaughter houses of Dinajpur town for detailed histomorphological examinations during the period from $1^{\text {st }}$ July 2014 to 30 June 2015 . Non infected goat was reared in the farmer house.

\subsection{Experimental animals}

The experimental animals of this study were goats those submitted for slaughtering in the slaughter house. The experimental animals were two types such as- Black Bengal goats affected with fascioliasis and Black Bengal goats not affected with fascioliasis.

\subsubsection{Selection of Black Bengal goats affected with fascioliasis}

Black Bengal goats affected with fascioliasis were primarily selected from Butchers house by observing clinical signs and symptoms such as- 
Pallor of the mucous membranes and development of anaemia, emaciation and progressive loss of body condition, submandibular oedema and ascites (bottle jaw), loss of appetite, diarrhoea, ruffled hair coat, distended and painful abdomen, disinclination to move, significant effect on production etc. which are tentative diagnosis of fasciolosis, confirmative diagnosis of fascioliasis was done by observing live parasites in the liver, bile duct and gall bladder of slaughtered goat. Faeces examination was done in the laboratory of Department of Anatomy and Histology to identify the eggs of Fasciola gigantica. Age of the goats was determined by dentition.

\subsubsection{Selection of Black Bengal goats not affected with fascioliasis}

Selection of Fasciola non affected goat was confirmed by faeces examination under McMASTER method which is as follows-

This method is based on the principle that the eggs are floated up in a counting chamber. A special type of slide devised by McMaster is required in this technique. Two glass slides joined together and the space between them divided to form two counting chambers of $0.15 \mathrm{ml}$ capacity each is the McMaster slide. In this method a known volume of faeces ( 5 to $10 \mathrm{~g}$ ) is thoroughly suspended in a known volume (50 to $100 \mathrm{ml}$ ) of saturated salt solution (sp.gr. 1.2). The suspension may be strained through a $150 \mathrm{~mm}$ mesh sieve to remove the coarse particles. A portion of the suspension is withdrawn with the help of a pasteur pipette or with an ordinary plastic transfer pipette, and allowed to run into the chambers of the McMaster slide. The slide is stand for 3 to 5 minutes to allow the eggs to float. The eggs in the two chambers are counted using low powers objectives (X10) and eyepiece (X10). The number of eggs per faeces may be calculated by using the following formula:

Number in one gram $=\frac{\text { Number in two chamber }}{0.3} \times$ dilution factor ${ }^{*}$

${ }^{*}$ Dilution factor $=\frac{\text { Total volume of supensin in } \mathrm{ml}}{\text { Total volume of faeces }}$

Negative result i.e absence of Fasciola gigantica eggs was confirmed that goat was not infected with fascioliasis. Age of the goat was determined by dentition.

\subsubsection{General management of goats not affected with fascioliasis}

After confirmation regular anthelmintic was used to prevent the further infection upto slaughter. The goat was reared in conventional farming system. There was semi-concrete floor system for experimental goat. Surface of the floor was even bedding material. There is both natural and artificial air flow in the house. Both roughage and green grass were offered to him. Sometimes they were supplied Jackfruit leaves, Banana leaves, Mango leaves etc. Concentrates supplied by the farmers were rice polish, wheat bran ,anchor bran, boiled rice, broken maize, broken rice, tiloil cake, mustard oil cake, pulse husk, salt etc. Regular vaccination was done for the goat to prevent the contagious diseases.

\subsection{Gross morphological examination}

A total of 10 affected and 10 non affected livers along with gall bladders showing grossly visible abnormalities were collected for detailed morphological studies. The length and girth of the livers and gall bladders were measured by using measuring tape. The weight of the livers and gall bladders was measured by using digital weight machine. All the changes were noted. Incisions were given to the affected area to study the nature or the macroscopic cessions, whenever needed. The blood vessels and biliary ducts were opened with the help of scissors and forceps and the liver flukes were collected. The liver was then cut into small slices and the slices were squeezed and macerated in normal saline. After careful removal of larger debris's the smaller ones was washed several times with normal saline until the supernatant fluid was clear. The sediment was then examined thoroughly for parasites, sometimes with the aid of a magnifying glass. The collected trematodes were washed in normal saline and distilled water for several times and preserved in glycerin alcohol solution which was composed 95 parts of 70 percent ethyl alcohol and 5 parts of glycerine. The parasites were identified in the Department of Anatomy and Histology, Faculty of Veterinary and Animal Science, Hajee Mohammad Danesh Science and Technology University.

\subsection{Microscopic examination}

During slaughter, affected and non affected livers having gross lesions were collected then preserved at $10 \%$ formalin, after that processed, sectioned and stained for histopathological studies following a standard procedure (Luna, 1968). 


\subsection{Statistical analysis}

The data recording the study of the affected and non affected livers were tabulated and subjected to analysis. Statistical analysis of the data was done by paired t- test using SPSS 10.0 programme. The weight, length and girth between the affected and non-affected livers were compared by t-test.

\section{Results}

On gross and microscopic examination of 10 non affected and 10 affected gall bladders and bile ducts by fascioliasis in Black Bengal goat that were collected freshly from different slaughter houses were subjected for different examinations. The comparative biometry (weight, length, girth) of the non affected and affected gall bladders by fascioliasis in Black Bengal goat was shown in Table 1. The average weight of affected gall bladder was $26.10 \pm 0.70 \mathrm{gm}$ which was significantly $(\mathrm{p}<0.001)$ higher than non affected gall bladder $(19.40 \pm 0.96 \mathrm{gm})$. The average length and girth of affected gall bladder were $10.30 \pm 0.37 \mathrm{~cm}$ and $8.24 \pm 0.30 \mathrm{~cm}$, respectively which were also significantly $(p<0.001)$ higher than the length $(6.10 \pm 0.30 \mathrm{~cm})$ and Girth $(5.85 \pm 0.25 \mathrm{~cm})$ of non affected gall bladder of Black Bengal Goat. Two types of changes were recorded during the course of study. These were gross changes and microscopic changes. Two forms of fascioliasis were found during these investigation namely acute and chronic infections.

\subsection{Gross changes of bile duct}

Thickening of the bile ducts and fibrosis in a portal area due to chronic fascioliasis was found in case of affected bile duct but were not found in case of non affected liver (Figure $3 \& 4$ ). Sections of immature flukes surrounded by clear spaces were found in the dilated and thickened bile ducts. A brownish exudates and a number of mature Fasciola gigantica were found in the lumen. The adult Fasciola gigantica was noticed in cross section in the lumen of the thickened bile ducts (Figure 5 and Figure 6). Early of the flukes into the bile ducts resulted in proliferation of the epithelium producing a granular mucosa which was found in the present study. Acute pathological lesions could only be produced by developing flukes prior to their entry to the bile ducts. In chronic Fasciola gigantica infections 3 types of chronic reaction were observed: numerous small abscesses containing Fasciola larvae or eggs with cellular reactions; marked inter lobular fibrosis, proliferation of bile ducts and paramilitary fibrosis in absence of parasites; and nodular growths consisting of hyper plastic bile ductless lacking secretary ability (Figure 6).

\subsection{Microscopic changes of bile duct}

Microscopically the epithelial layer of the bile ducts were seen to the partially disintegrated, but simultaneous proliferation of epithelial cells occurred. Thickening of the bile ducts was the result of connective tissue proliferation. Minute cytoplasmic blebs at the free margin of the epithelial lining cells seemed to be the first indication of what become an intense hyperplasia of the tubular outgrowths and an associated fibrosis in the underline connective tissue. Formation of new bile ducts and deposition of bile pigment in the tissue space were seen in the affected liver but absence in non-affected liver (Figure 11 and Figure 12). When the flukes invade the bile duct their spine and suckers quickly abrade the superficial cells and they feed on the tissue debris so produced. Bile duct in some parts showed periductal cellular infiltrations, mainly neutrophiles, lymphocyte and eosinophiles. Brilliant cells, were demonstrated in the beneath epithelium of infected goat but not seen in case of non-infected goat. No calcification in the wall of the bile ducts in chronic Fascioliasis in goat could be seen in this study. The bile ducts revealed hyperplastic changes of the lining epithelial cells, which at times assumed papillomatous proportion. Most of the ducts were, however devoid of the lining epithelial cells as a result of the movement of flukes within the ducts. Later the biliary epithelium became proliferated partial or complete occlusion of bile ducts and wall of the bile ducts become fibrosis in infected goat. They consisted of collections of hepatic epithelial cells in a state of coagulative necrosis or in the process of disappearing surrounded by a thin sprinkling of neutrophils and lymphocytes.

\subsection{Gall bladder}

Gall bladder of Fasciola affected Black Bengal Goat also shows some deviation from the structures of gall bladder of fasciola non-affected Black Bengal Goat. The gross and microscopic changes that were found in the gall bladder of fasciola affected black Bengal goat are described below:

\subsubsection{Gross changes of gall bladder}

The major gross changes of gall bladder of fasciola affected black Bengal goat were; the gall bladder was very dark usually contained blood clots, the consistency of bile was also very dense. Thickening of the epithelium of 
gall bladder and fibrosis was observed in this study. Presence of adult parasites in the lumen of gall bladder was also found in this research work. Dilatation and distention of gall bladder was a fate of chronic fascioliasis (Figure 7 and Figure 8).

\subsubsection{Microscopic changes of gall bladder}

The microscopic changes due to acute and chronic fascioliasis were characterized by hyperplasia of the tubuloalveolar glands, increases in the number of enterochromaffin cells and of the large cells containing eosinophilic granules where as no hyperplasia was found in case of non infected goat. Numerous eggs were seen in the bile of infected goat which were absence in case of non infected goat.

\section{Discussion}

The average weight of affected gall bladder was $26.10 \pm 0.70 \mathrm{gm}$ which was significantly $(\mathrm{p}<0.001)$ higher than non affected gall bladder $(19.40 \pm 0.96 \mathrm{gm})$. The average length and girth of affected gall bladder were $10.30 \pm 0.37 \mathrm{~cm}$ and $8.24 \pm 0.30 \mathrm{~cm}$, respectively which were also significantly $(\mathrm{p}<0.001)$ higher than the length $(6.10 \pm 0.30 \mathrm{~cm})$ and Girth $(5.85 \pm 0.25 \mathrm{~cm})$ of non affected gall bladder of Black Bengal Goat. The result is closely agreed with Getty (1975) who stated that average length of gall bladder of ox was $10 \mathrm{~cm}$ to $15 \mathrm{~cm}$. The variation in length of gall bladder may be due to variation in species.

\subsection{Gross changes of bile duct}

Thickening of the bile ducts and fibrosis in a portal area due to chronic Fascioliasis also found. Formation of new bile ducts and deposition of bile pigment in the tissue space were seen. Migratory tract with lymphocytic infiltration was more common case. Sections of immature flukes surrounded by clear spaces were found in the dilated and thickened bile ducts. A brownish exudates and a number of mature Fasciola gigantica were found in the lumen. The adult Fasciola gigantica was noticed in cross section in the lumen of the thickened bile ducts. No calcification in the wall of the bile ducts in chronic Fascioliasis in goat could be seen in this study. Similarly, according to Simesen (1968) and Pullan et al. (1970), the bile ducts of the liver in sheep never calcified, contrary to findings in cattle Ross, 1966 and Dow et al. (1967). Ross et al. (1967) reported that there was no calcification in the pig liver in chronic Fascioliasis. The difference in calcification might be due to species variation. Early of the flukes into the bile ducts resulted in proliferation of the epithelium producing a granular mucosa which was found in the present study. Ross et al. (1967) described similar pathological changes in acute fascioliasis in calves and pig livers, respectively. Acute pathological lesions could only be produced by developing flukes prior to their entry to the bile ducts. The result is similar to Ross (1966). In chronic Fasciola gigantica infections different types of chronic reaction were observed: numerous small abscesses containing Fasciola larvae or eggs with cellular reactions; marked inter lobular fibrosis, proliferation of bile ducts and paramilitary fibrosis in absence of parasites; and nodular growths consisting of hyper plastic bile ductless lacking secretary ability. The similar result was reported by Uzoukwu and Ikeme (1978) who found three types of chronic reaction in chronic Fascioliasis.

\subsection{Microscopic changes of bile duct}

Microscopically the epithelial layer of the bile ducts were seen to the partially disintegrated, but simultaneous proliferation of epithelial cells occurred. Thickening of the bile ducts was the result of connective tissue proliferation. Similar results were observed by Stenius (1963). Minute cytoplasmic blebs at the free margin of the epithelial lining cells seemed to be the first indication of what become an intense hyperplasia of the tubular outgrowths and an associated fibrosis in the underline connective tissue. When the flukes invade the bile duct their spine and suckers quickly abrade the superficial cells and they feed on the tissue debris so produced. The observations are closely agreed with Dawes (1963) who worked on various stages which was brought about in the epithelial lining of the bile duct while the young Fasciola hepatica were moving through the hepatic parenchyma before reaching the bile duct but he also recorded that chemical agencies and inflammatory process were probably responsible for these changes. According to Rahko (1969) bile duct in some parts showed periductal cellular infiltrations, mainly neutrophiles, lymphocyte and eosinophiles. Brilliant cells, were demonstrated in the beneath epithelium of infected cattle were closely agreed with the present study of infected goat. Similar result was found by Smith et al. (1972) and Bostelmann et al. (2000). The bile ducts revealed hyperplastic changes of the lining epithelial cells, which at times assumed papillomatous proportion. Most of the ducts were, however devoid of the lining epithelial cells as a result of the movement of flukes within the ducts. Later the biliary epithelium became proliferated partial or complete occlusion of bile ducts and wall of the bile ducts become fibrosis. They consisted of collections of hepatic epithelial cells in a state of coagulative necrosis 
or in the process of disappearing, mingled with of surrounded by a thin sprinkling of neutrophils and lymphocytes. More or less similar results were reported by Simesen (1968), Stenius (1963) and Bostelmann et al. (2000). Numerous eggs were seen in the bile the parenchyma the granulomatous lesions due to eggs were reported in the present study which was fully agreed with Uzoukwu and Ikeme (1978) and partially agreed with Ross and Dow (1966).

\subsection{Gross changes of gall bladder}

The major gross changes of gall bladder of fasciola affected black bengal goat were; the gall bladder was very dark usually contained blood clots, the consistency of bile was also very dense. Thickening of the epithelium of gall bladder and fibrosis was observed in this study. Presence of adult parasites in the lumen of gall bladder was also found in this research work. Dilatation and distention of gall bladder was a fate of chronic fascioliasis was the more or less similiar result reported by Asdrubali and Mughetti (1966).

\subsection{Microscopic changes of gall bladder}

The microscopic changes due to acute and chronic fascioliasis were characterized by hyperplasia of the tubuloalveolar glands, increases in the number of enterochromaffin cells were the more or less similiar result also reported by Asdrubali and Mughetti (1966).

Table 1. Comparative biometry of affected $(n=10)$ and non-affected $(n=10)$ gall bladder by fascioliasis in Black Bengal goat.

\begin{tabular}{llll}
\hline Parameters & Type of Gall Bladder & Mean $\pm \mathbf{S E}$ & Significance \\
\hline \multirow{2}{*}{ Weight $(\mathrm{gm})$} & Affected Gall Bladder & $26.10 \pm 0.70$ & $* * *$ \\
& Non Affected Gall Bladder & $19.40 \pm 0.96$ & \\
\multirow{2}{*}{ Length $(\mathrm{cm})$} & Affected Gall Bladder) & $10.30 \pm 0.37$ & $* * *$ \\
& Non Affected Gall Bladder & $6.10 \pm 0.30$ & \\
\multirow{2}{*}{ Girth $(\mathrm{cm})$} & Affected Gall Bladder & $8.24 \pm 0.30$ & $* * *$ \\
\hline
\end{tabular}

$\mathrm{SE}=$ Standard Error, $(* * *)=$ Highly significant $(\mathrm{p}<0.001), \mathrm{n}=$ number of sample

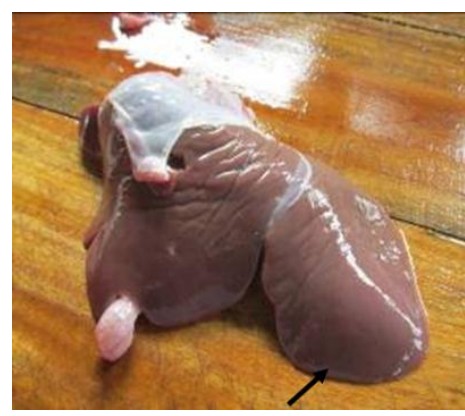

Figure 1. Liver not affected with fascioliasis show normal elongated edge.

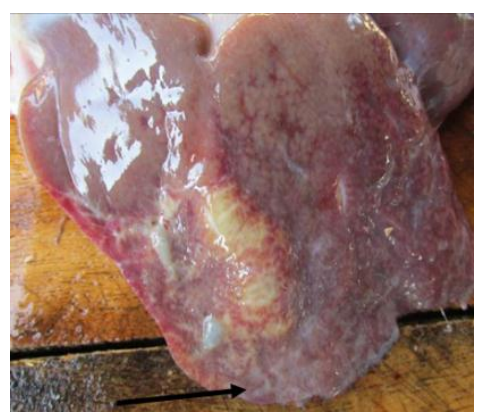

Figure 2. Liver affected with fascioliasis show swollen and rounded edge. 


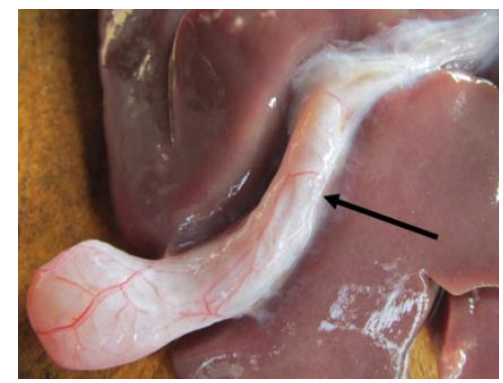

Figure 3. Normal structure where no thickening and fibrosis occurred in infected goat.

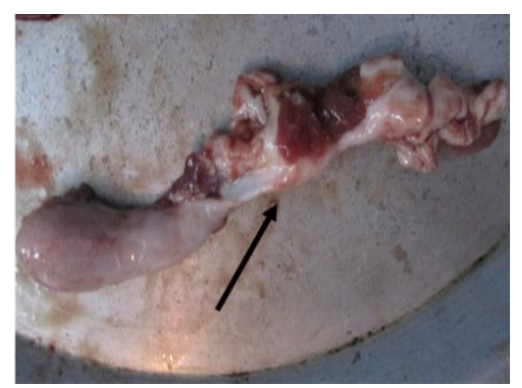

Figure 4. Thickening and fibrosis of bile duct of infected goat.

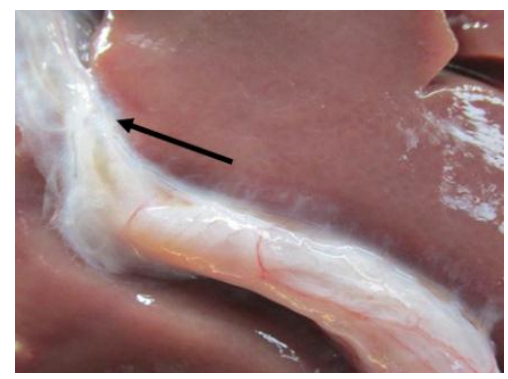

Figure 5. No fibrosis of bile duct and no adult flukes found in the non-affected liver.

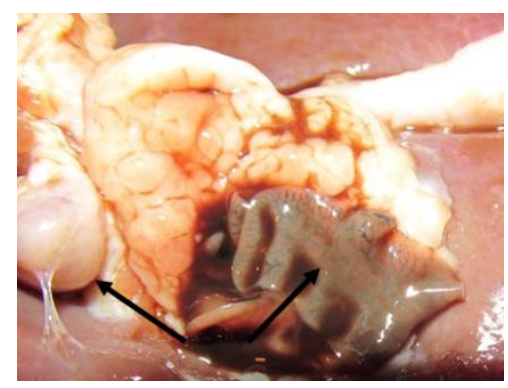

Figure 6. Fibrosis of bile duct containing adult flukes and nodule in the affected liver.

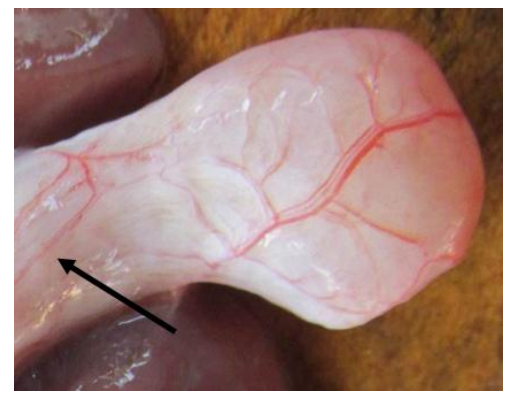

Figure 7. No parasite in the lumen of gall bladder of non-infected goat. 


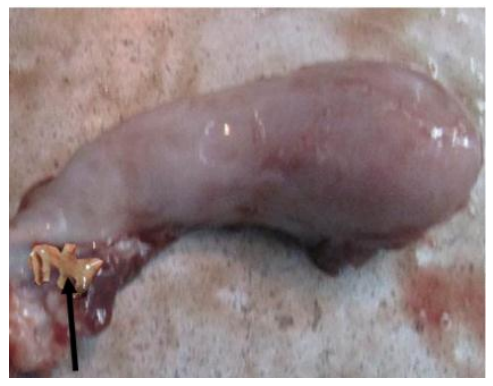

Figure 8. Adult parasite in the lumen of gall bladder of infected goat.

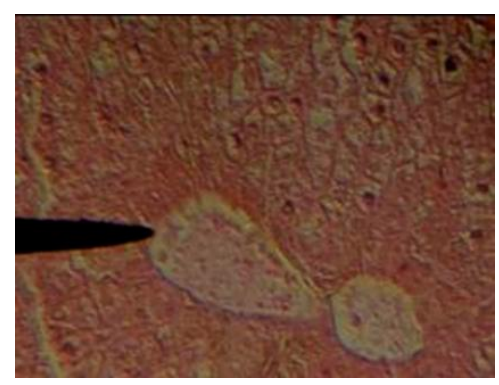

Figure 9. Normal portal triad were observed in the non-affected liver. (H \& E X 10).

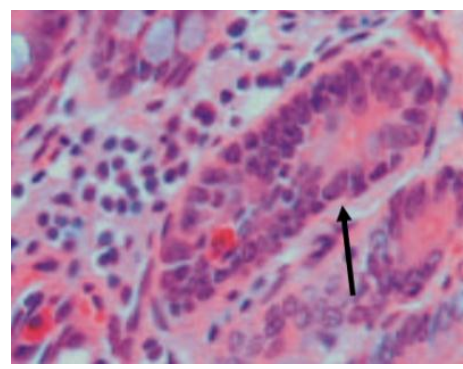

Figure 10. Hyperplasia, fibrous connective tissue and closure portal triad were observed in the affected liver. (H \& E X 40).

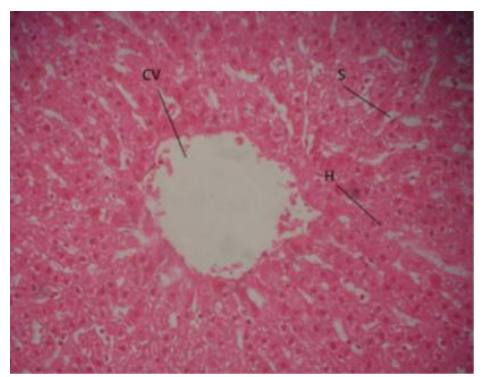

Figure 11. No bile pigment was observed in the tissue space of non-affected liver. $\mathrm{S}$ (Sinusoid) $\mathrm{H}$ (Hepatocyte), CV (Central Vein) (H \& E X 10).

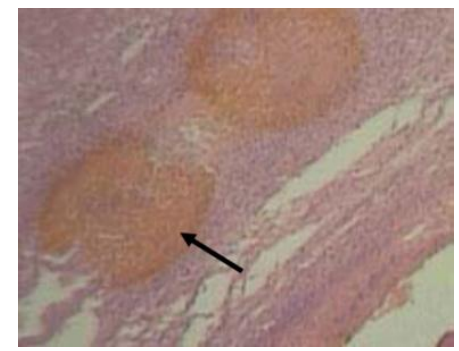

Figure 12. Deposition of bile pigment in the tissue space of affected liver ( $H \& E X 10)$. 


\section{Conclusions}

Liver of Black Bengal goats are mostly affected with parasitic disease like fascioliasis. Present study was revealed not only liver but also bile duct and gall bladder are mostly affected with fascioliasis. Fascioliasis (Fasciola gigantica) is greatly responsible for damaging bile duct and gall bladder of Black Bengal goat and demands immediate attention for taking control and eradication measures. Bile duct and gall bladder of male and female goats both sexes were found to be affected with fascioliasis but severity is higher in Female goats than those of male goats. Fascioliasis (Fasciola gigantica) is one of the major causes of reduction of meat production of Black Bengal goats. The prevalence of fascioliasis (Fasciola gigantica) is higher in older animals. Regular anthelmintic should be used in case of Black Bengal goat from very early age to avoid infection by fascioliasis. Infected goat should be administered proper anthelmintic at proper dose without any delay. Balanced diet and proper housing system should be maintained to avoid fascioliasis.

\section{Acknowledgement}

Authors are thankful to the Department of Anatomy and Histology, Faculty of Veterinary and Animal Science, Hajee Mohammad Danesh Science and Technology University, Dinajpur. They also grateful to the goat farmers and butchers of the slaughter houses for helping during the research work.

\section{Conflict of interest}

None to declare.

\section{References}

Acosta-Fereira W, J Vercelli-Ratta and LM Falconi, 1979. Fasciola hepatica human infection, histopathological study of 16 cases. Virchows Arch. A. Pathol. Anat. Histol., 23: 319-327.

Amin MR, 2000. Genetic improvement of production traits in Black Bengal goats by selective breeding and crossbreeding. Ph.D. Thesis, Department of Animal Breeding and Genetics, Bangladesh Agricultural University, Mymensingh.

Amin MR, SS Husain, ABMM Islam and M Saadullah, 2001. Direct selection response to growth and correlated response to lactation traits in Black Bengal goats. Asian - Australatian. J. Anim. Sci., 14: 899-904.

Ansari-Lari M and M Moazzeni, 2006. A retrospective survey of liver fluke disease in livestock based on abattoir data in Shiraz, south of Iran. Prev. Vet. Med., 73: 93-96.

Asdrubali G and L Mughetti, 1966. Changes in the gall bladder of cattle with fascioliasis. Atti. Soc. Ital. Sci., 20: 553-557.

Chowdhury SA, MSA Bhuiyan and S Faruque, 2002. Rearing Black Bengal goat under semi-intensive management 1 . Physiological and reproductive performances. Asian - Australatian. J. Anim. Sci, 15: 477484.

Devendra C and N Burns, 1983. Goat production in the tropics. Commonwealth Bureaux of Animal Breeding and Genetics. Commonwealth Agricultural Bureaux, Farnham Royal, UK Technical Communication, pp. 19:183.

Diaw DT, M Seye and Y Sarr, 1998. Epidemiology of trematodiases in livestock in the Kolda region, Casamance. Rev. Elev. Med. Pays .Vet Trop., 41: 257-264.

Dow C, JG Ross and JR Todd, 1967. The pathology of experimental Fascioliasis in calves. J. of comparative Path., 77: 377-385.

Epsterin H, 1971. The origin of the domestic animals of Africa, Africa Publishing Corporation, New York, London and Munich.

Getty R, 1975. Sisson and Grossman's the Aanatomy of the Domestic Animals. Vol. 1. $5^{\text {th }}$ edn. W. B. Saunders Company. p. 913.

Hammond JA and MMH Sewell, 1990. Diseases caused by helminthes. In: M M H Sewell and D W Brocklesdy Handbook on Animal Diseases in the Tropics, $4^{\text {th }}$ edition. CTVM. Edinb. Uni. pp. 119-123.

Herre W and M Röhrs, 1973. Haustiere-Zoologisch gesehen (Compendium of basic data).

Husain SS, MR Amin and ABMM Islam, 1998. Goat production and its breeding strategy in Bangladesh. First National Workshop on Animal Breeding. Bangladesh Agricultural University, Mymensingh. 26 November, 1998. pp. 17-36.

Jabber MA and HAG Green, 1983. The status and potential livestock within the context of agricultural development policy in Bangladesh. Aberystwyth: The University of wales: 113 str.

Luna LG, 1968. Manual of Histologic Staining Methods of the Armed Forces Institute of Pathology. $3^{\text {rd }}$ edn., MC Ggraw Hill Book Co, New York. 
Menkir MS, A Uggla and PJ Waller, 2007. Prevalence and seasonal incidence of nematode parasites and fluke infections of sheep and goats in eastern Ethiopia, Trop. Anim. Helth. Prod., 39: 521-531.

Pullan NB, MMH Sewell and JA Hammond, 1970. Studies on the pathogenecity of massive infections of Fasciola hepatica in lambs. Helm. Abstr., 40: 2267.

Rahko T, 1963. The pathology of natural Fasciola hepatica infection in Cattle. Helm. Abstr. 40: 2270.

Islam MR, MNH Parvez and MJU Sarder, 2015. Comparative histomorphological study of non affected and affected liver by fascioliasis in Black Bengal goat. Asian J. Med. Biol. Res., 1: 424-433

Roberts HE, 1968. Observations on experimental acyte fascioliasis in sheep. Br. Vet. J., 124: 433-450.

Ross JG, 1966. An Abattoir survey of cattle liver infections with Fasciola hepatica. Br. Vet. J., 122: 489-494.

Ross JG, C Dow and JR Todd, 1967. The pathology of Fasciola hepatica infection in pigs: A comparison of the infection in pigs and other hosts. Br. Vet. J., 123: 317-322.

Sengupta T and PKR Lyer, 1968. Studies on the pathology of buffalo livers infested with fasciolia gigantica. Ind. J. Anim. Hlth., 7: 111-119.

Shirai W, 1963. Histopathological studies on bovine liver affected by fasciolia hepatica with spetial reference to the brilliant cells. Jap. J. Vet. Sci., 25: 193-199.

Simesen MG, 1968. Chronic fascioliasis in sheep. I. Clinical, Clinical- pathological and histopathological studies. Helm. Abstr., 40: 4850.

Smith HA, TC Jones and RD Hunt, 1972. Veterinary Pathology, $4^{\text {th }}$ edn. Lea and Febiger, Philadelphia, pp.715716, 794-800 and 1230-1231.

Soulsby EJL, 1982. Helminthes, Arthropods and protozoa of Domesticated Animals, $7^{\text {th }}$ end. The English language Book society and Baillire Tindal. London; pp. 51-65.

SPSS, Windows for version-10.0.Release on 27. 10. 1999 (Microsoft crop.1988) trends. SPSS Inc. Michigan Avenue, Chicago.

Swai ES and E Ulicky, 2009. An evaluation of the economic losses resulting from condemnation of cattle livers and loss of carcass weight due to fasciolosis: a case study from Hai town abattoir, Kilimanjaro region, Tanzania. Livestock Research for Rural Development. Volume 21, Article. 186.

Uzoukwn M and MM Ikeme, 1978. Hepatic changes in natural Fasciola gigantic infections of Fulani Zebu. Bull. Anim. Health Prod. Afr., 48: 4574.

WHO (World Health organization), 2006. Animal production and health paper No.78. USA. 